\title{
Topical application of double-stranded RNA molecules deriving from Tomato yellow leaf curl virus reduces cognate virus infection in tomato
}

\author{
O. MELITA ${ }^{1}$, A. KALDIS ${ }^{1}$ iD, M. BERBATI ${ }^{1}$, C. REPPA $^{2}$, M. HOLEVA ${ }^{2}$ (D) M. LAPIDOT $^{3}$ iD \\ D. GELBART ${ }^{3}$, P. OTTEN ${ }^{4}$, and A. VOLOUDAKIS ${ }^{1, *}$ (iD
}

${ }^{1}$ Laboratory of Plant Breeding and Biometry, Agricultural University of Athens, Athens 11855, Greece

${ }^{2}$ Laboratory of Bacteriology, Benaki Phytopathological Institute, Kifissia 14561, Greece

${ }^{3}$ Department of Vegetable and Field Crops, ARO, The Volcani Center, 7505101, Rishon Le Zion, Israel

${ }^{4}$ Fasteris SA, Plan-les-Ouates, Geneva 1228, Switzerland

${ }^{*}$ Corresponding author: E-mail: avoloud@aua.gr

\begin{abstract}
Tomato yellow leaf curl virus (TYLCV), a whitefly-transmitted single-stranded DNA (ssDNA) virus, causes the most important viral disease of tomato worldwide. TYLCV-mediated disease is mainly controlled via extensive insecticide sprays aiming at the whitefly vector. RNA-based vaccination was proven to be a non-transgenic approach leading to efficient plant virus control. In this work, double-stranded RNA (dsRNA) molecules deriving from sequences of the C4 and V2 genes of TYLCV-Mild were produced in vitro and topically applied onto tomato plants along with the virus (via agroinfiltration). DsC4 and dsV2 application reduced disease incidence to 23 and $46 \%$, respectively, while TYLCV positive control reached $64 \%$. Bioinformatics analysis of the virus-specific small interfering RNAs (vsiRNAs) from TYLCV-infected tomato revealed 'hot' and 'cold' spots in the TYLCV-Mild genome. Interestingly, the viral C-strand had twofold siRNA reads when compared to that of the V-strand. Overall, vsiRNAs of negative and positive polarity were almost equal (53.5 vs. $46.6 \%$ ); vsiRNAs of negative polarity prevailed at the V-strand. Stem-loop RT-PCR validated the presence of six vsiRNAs (hot or cold spots) in TYLCV-Mild-infected and dsRNA-treated tomato. The exogenously applied dsRNA was found to rapidly move systemically in tomato and was detected for 54 days post treatment (dpt). The applied dsRNA molecules were successfully processed by the Dicer-like proteins (DCLs) in tomato since small interfering RNAs (siRNAs) deriving from the dsRNA were detected for at least $54 \mathrm{dpt}$. This consists the first report of dsRNA-based vaccination applied against a monopartite geminivirus.
\end{abstract}

Keywords: next generation sequencing, RNA silencing, siRNAs, Solanum lycopersicum.

$\overline{\text { Received }} 23$ July 2020, last revision 8 December 2020, accepted 14 December 2020.

Abbreviations: DCLs - dicer-like proteins; dNTPs - deoxynucleotide triphosphates; dpi - days post infection; dpt - days post treatment; dsRNA - double-stranded RNA; IR - intergenic region; LB - Luria-Bertani; NGS - next generation sequencing; Nt - nucleotide; ORFs open reading frames; PCR - polymerase chain reaction; RNAi - RNA interference; RT - reverse transcription; siRNAs - small interfering RNAs; ssDNA - single-stranded DNA; TYLCV - Tomato yellow leaf curl virus; TYLCSV - Tomato yellow leaf curl Sardinia virus; vsiRNAs - virus-specific small interfering RNAs.

Acknowledgements: We would like to thank GEORION Ltd. for the cooperation and providing the tomato plant material; Dr E. Moriones for providing the TYLCV-Mild strain. This work was supported by the project sRNAvac, entitled "Small RNA-mediated antiviral agri-technology", funded by the General Secretariat of Research and Technology (GSRT) of Greece under the bilateral R\&T projects Greece-China 2012-2014.

Conflict of interest: The authors declare that they have no conflict of interest. 


\section{Introduction}

Tomato yellow leaf curl virus (TYLCV) was first identified in Jordan valley and then spread through the Middle East, the Mediterranean basin and from there globally (Lefeuvre et al. 2010). TYLCV (genus Begomovirus, family Geminiviridae) presents great genome variability and high recombination rate. The circular ssDNA genome of approximately 2800 bases, consists of six partially overlapping open reading frames (ORFs) organized in both directions in two transcriptional units [viral (V) strand and complementary (C) strand] separated by an intergenic region (IR) of about 300 nucleotides (Fig. $1 \mathrm{~A}$ Suppl.). The IR possesses the key-elements for genome replication and transcription. The V-strand includes two overlapping ORFs, V1 (coat protein) and V2 (viral RNA silencing suppressor; RSS). V2 was found to inhibit RNA silencing of a reporter transgene, targeting a subsequent step in dsRNA processing by DCLs, in the RNA silencing pathway (Zrachya et al. 2007a). V2's role as an RSS is further supported by its interaction with SISGS3, the tomato homolog of the Arabidopsis SGS3, known to be involved in the RNA interference (RNAi) pathway (Glick et al. 2008). Moreover, V2 was found to bind the tomato CYP1 protein, a member of the family of papain-like cysteine proteases that are involved in plant defense against pathogens via hypersensitive response (Bar-Ziv et al. 2015). The C-strand contains four ORFs (C1-C4), from which $\mathrm{C} 1-\mathrm{C} 2$ and $\mathrm{C} 2-\mathrm{C} 3$ are partially overlapping, and C4 is positioned within C1 (Gafni 2003) (Fig. 1A Suppl.). $\mathrm{C} 1$ encodes a protein involved in viral replication, $\mathrm{C} 2 \mathrm{a}$ transcription activator protein, $\mathrm{C} 3$ a replication enhancer protein, and $\mathrm{C} 4$ a protein involved in virus movement (Jupin et al. 1994, Díaz-Pendón et al. 2010). C4 is located at the host cell periphery (Rojas et al. 2001), associated with the plasmodesmata (Hak et al. 2015). C4 was also found to suppress post-transcriptional gene silencing (PTGS) for the bipartite begomoviruses African cassava mosaic virus [ACMV-(CM)] and Sri Lankan cassava mosaic virus (SLCMV) (Vanitharani et al. 2004). Furthermore, Chellappan et al. (2005) found that C4 of ACMV binds to and possibly inactivates mature microRNAs (miRNAs), thus affecting the normal miRNA-mediated regulation of target mRNAs.

Tomato yellow leaf curl disease (TYLCD) is caused by a complex of TYLCV variants inducing leaf curling, leaf yellowing, stunting, chlorotic/yellow mosaic, flower abortion and up to $100 \%$ losses on plant production (Moriones and Navas-Castillo 2000). Besides tomato, Phaseolus vulgaris, Capsicum annuum (Díaz-Pendón et al. 2010), and ornamental plants (e.g. Petunia spp.) are susceptible; wild plants species and weeds can serve as natural virus reservoirs. TYLCV is divided into two phylogenetic strains, TYLCV-IL and TYLCV-Mild, with the former being the type strain. Tomato yellow leaf curl Sardinia virus (TYLCSV) is considered a separate species (Brown et al. 2012). Other TYLCV-related species have been identified causing disease outbreaks in Europe that are considered TYLCV and TYLCSV recombinants (Garcia-Andres et al. 2006) or newly emerged species targeting new hosts (Juárez et al. 2014).

Outbreaks of TYLCD in tomato heavily depend on virus transmission (persistent and circulative) by its vector, the whitefly Bemisia tabaci (Hemiptera: Aleyrodidae), being itself a complex species (De Barro et al. 2011). The current TYLCV control measures involve intense insecticide sprays against its vector and introgression of resistant or tolerant genes from wild species to cultivated tomato through breeding (Lapidot and Levin 2017). The latter is time-consuming and may be overcome due to TYLCV genome evolution. Thus, scientists turned to plant genetic engineering to apply pathogen derived resistance (PDR) (Sanford and Johnston 1985). Transgenic tomato plants expressing the TYLCV V1 gene (Zrachya et al. 2007b), part of the $C 1$ gene (Antignus et al. 2004), an intron-hpRNA, part of C1 gene (Fuentes et al. 2016), or harboring three conserved TYLCV sequences (Leibman et al. 2015), as well as transgenic Nicotiana benthamiana plants expressing the $\mathrm{C} 1$ antisense RNA (Bendahmane and Gronenborn 1997) or part of the C1 (Noris et al. 1996), have provided short- or long-term TYLCV resistance. A number of the aforementioned approaches exploit the plant antiviral RNA silencing mechanism (RNAi), involving the recognition of dsRNA or stem-loop RNA structures by DCLs which cleave them to 21 - 25 bp siRNAs. These siRNAs together with the argonaute proteins (AGOs) form the RNA-induced silencing complex (RISC), leading to the degradation of the homologous mRNA target (Duan et al. 2012). Recently, a non-transgenic approach has been tested exploiting the host's RNAi machinery to induce resistance against plant viruses (Voloudakis et al. 2015). This method was designated as dsRNA-based vaccination and was applied successfully against RNA viruses: Pepper mild mottle virus, Tobacco etch virus, Alfalfa mosaic virus (Tenllado and Díaz-Ruíz 2001), Cucumber mosaic virus (Holeva et al. 2021, Borah et al. 2018, Namgial et al. 2019), Tobacco mosaic virus (Yin et al. 2009, Konakalla et al. 2016), Zucchini yellow mosaic virus (Kaldis et al. 2018), Sesbania mosaic virus (Konakalla et al. 2019), and Papaya ringspot virus (Vadlamudi et al. 2020). Recently, dsRNA-based vaccination was found to be functional against the DNA virus Tomato leaf curl virus (Namgial et al. 2019).

The aim of this study was to induce resistance to tomato against TYLCV, a DNA virus, employing the dsRNAmediated vaccination, by topical application of dsRNA molecules of C4 and V2 genes of TYLCV-Mild strain that were selected as targets due to their silencing suppressor activity. DsRNA molecules were processed in tomato and moved systemically very fast upon introduction to plants and persisted for at least $54 \mathrm{dpt}$ in planta. Deep sequencing was used to determine the degradation products of the TYLCV-Mild genome.

\section{Materials and methods}

Plants and viral inoculums: Tomato plants (Solanum lycopersicum L. cv. Clodin) were used in bioassays at the Agricultural University of Athens (AUA), Greece. 
Plants were inoculated at the $3^{\text {rd }}-4^{\text {th }}$ true leaf stage and were maintained in an insect-proof greenhouse (day/ night temperatures of $22-25{ }^{\circ} \mathrm{C}, 16 / 8$-h light/dark, an irradiance of $100 \mu \mathrm{mol} \mathrm{m} \mathrm{m}^{-2} \mathrm{~s}^{-1}$, and a relative humidity of $65 \%$ ). Plant inoculation was performed by agroinfiltration of the Agrobacterium tumefaciens LBA4404 harboring the TYLCV-Mild strain (AF071228.1, Navas-Castillo et al. 2000).

Nucleic acid extraction: Total plant DNA was obtained employing the cetyltrimethylamonnium bromide (CTAB) extraction protocol (Stewart and Via 1993) or the Dellaporta protocol (Dellaporta et al. 1983) using tomato leaf tissue systemically infected with TYLCV-Mild, for in vitro dsRNA production, and for determination of TYLCV presence, respectively.

To obtain RNA for small RNA next generation sequencing analysis (NGS), top systemic leaf tissue from three plants per treatment was pooled and the mirVana miRNAisolation kit (Life technologies, Carlsbad, USA) was employed. To investigate dsRNA stability and movement, total RNA was extracted from local and systemic tomato leaf tissue, after topical dsRNA inoculation, using TRIzol (Thermo Fischer Scientific, Waltham, USA). For both methods, the manufacturer's instructions were followed.

DsRNA production deriving from the TYLCV-Mild V2 and C4 genes: DsRNA molecules were produced employing an in vitro method, comprising of a twostep PCR approach followed by in vitro transcription (Voloudakis et al. 2015, Konakalla et al. 2016, Kaldis et al. 2018). PCR products corresponding to the V2 and $\mathrm{C} 4$ genes of TYLCV-Mild (AF071228.1) were used as templates (Fig. 1A,B Suppl.). In the first step, V2 gene sequence (351 bp, 155-505) and almost the whole C4 gene sequence (294 bp, 2178-2471) were amplified using PCR primers with a linker sequence (GGGGATCC) at their 5' end, designed in this study using the Primer3 web tool (http://primer3.ut.ee/) (Table 1 Suppl.). Final concentration of the reaction components was: $0.2 \mathrm{mM}$ dNTPs, $0.4 \mu \mathrm{M}$ forward and reverse primer for V2 and 0.2 $\mu \mathrm{M}$ forward and reverse primer for $\mathrm{C} 4,0.4 \mathrm{U} K A P A \mathrm{Taq}$ DNA polymerase (KAPA Biosystems, Cape town, South Africa); PCR conditions were $95{ }^{\circ} \mathrm{C}-2 \mathrm{~min}, 35$ cycles of $95{ }^{\circ} \mathrm{C}-30 \mathrm{~s}, 56{ }^{\circ} \mathrm{C}-30 \mathrm{~s}, 72{ }^{\circ} \mathrm{C}-30 \mathrm{~s}$, followed by $72{ }^{\circ} \mathrm{C}$ - $5 \mathrm{~min}$. Dilutions of the amplified products, 1:1000 for V2 (367 bp) and 1:10 for C4 (310 bp) gene, respectively, were used as templates in a second PCR employing the T7linker primer(5'-GAGAATTCTAATACGACTCACTATA GGGGATCC-3'). Final concentration of the components was: $0.3 \mathrm{mM}$ dNTPs, $0.3 \mu \mathrm{M}$ T7 primer, $0.5 \mathrm{U}$ KAPA high fidelity DNA polymerase; PCR conditions were $95{ }^{\circ} \mathrm{C}$ - 2 min, 35 cycles of $95{ }^{\circ} \mathrm{C}-30 \mathrm{~s}, 50{ }^{\circ} \mathrm{C}-30 \mathrm{~s}, 72{ }^{\circ} \mathrm{C}$ - $30 \mathrm{~s}$, followed by $72^{\circ} \mathrm{C}-5 \mathrm{~min} .3 \mathrm{~mm}^{3}$ of the second PCR product of TYLCV-Mild_V2 or TYLCV-Mild_C4 gene, were used as a template for in vitro transcription $(T 7$ Ribomax ${ }^{\mathrm{TM}}$ Express large scale RNA production system, Promega, Madison, USA) with $10 \mathrm{~mm}^{3}$ of Ribomax ${ }^{\mathrm{TM}}$ Express $T 72 \times$ buffer, $6.5 \mathrm{~mm}^{3}$ of sterile ultrapure water, $20 \mathrm{U}$ enzyme mix (T7 Express); reaction was performed at $37{ }^{\circ} \mathrm{C}$ for $4.5 \mathrm{~h}$, followed by $10 \mathrm{~min}$ at $85^{\circ} \mathrm{C}$ and 20 min at $25{ }^{\circ} \mathrm{C}$. Resulting dsRNA_V2 and dsRNA_C4 concentration was estimated spectrophotometrically (Fisher Scientific Multiskan FC reader, Thermo Fisher Scientifics). For simplicity, the above mentioned dsRNAs are designated $\mathrm{ds} 22$ and $\mathrm{dsC} 4$, respectively, throughout the text.

Topical application of $\mathrm{dsV}_{2}$ and dsC4 molecules onto tomato plants inoculated with TYLCV-Mild via agroinfiltration: To investigate the protective effect of the produced dsRNAs on tomato against TYLCV-Mild, their topical application was performed in bioassays (five replications, Table 2 Suppl.) at Agricultural University of Athens (AUA). Treatments were: $a$ ) TYLCV (positive control), b) TYLCV + dsV2, c) TYLCV + dsC4, and $d$ ) water (negative control, mock). Ten tomato plants per treatment were used and two leaflets of different leaves per plant were treated. The dsRNA $(0.04-0.05 \mathrm{mg})$ was applied by rubbing the adaxial leaf surface of the same carborundum-dusted leaflet where the virus was agroinfiltrated. After dsRNA application, treated leaflets were washed off with tap water extensively.

TYLCV infection is accomplished in the laboratory via the efficient agroinfiltration method (Abhary et al. 2006). The dsRNA was applied at the same day as the TYLCV agroinfiltration. To determine whether dsRNA could be protective against TYLCV upon infection, in a preliminary experiment $\mathrm{dsV} 2$ was also applied $1 \mathrm{~d}$ after TYLCV agroinfiltration.

The plants of the above-mentioned treatments were agroinfiltrated with $A$. tumefaciens containing the infectious clone of TYLCV-Mild using a $1-\mathrm{cm}^{3}$ syringe lacking a needle at the abaxial leaf surface of the same two leaflets. For preparation of the virus inoculum, frozen bacterial stock of $A$. tumefaciens was grown in LB agar plate (containing $50 \mathrm{mg} \mathrm{dm}^{-3}$ kanamycin); a single colony was taken to grow in $5-\mathrm{cm}^{3}$ liquid LB (overnight incubation at $200 \mathrm{rpm}$ shaking and $28^{\circ} \mathrm{C}$ ). The latter was subcultured in liquid LB in $50-\mathrm{cm}^{3}$ flasks incubated at the same conditions. When the culture reached an absorbance at $600 \mathrm{~nm}\left(\mathrm{~A}_{600}\right)$ of $1.8-2.0$, it was centrifuged $(4000 \mathrm{~g}$ for $20 \mathrm{~min})$, the pellet was resuspended in $50-\mathrm{cm}^{3}$ sterile deionised water and the suspension was kept on ice until agroinfiltration. For negative control, plants were waterinfiltrated.

Treated plants were grown in the conditions mentioned above, and were observed for symptoms until $40-60 \mathrm{~d}$ post infection (dpi). The recording of symptoms was based on the following symptom severity scale: 0 - no symptoms; 1 - appearance of mosaic/leaf curl at the top of the plant/threading of new leaves or mottling at one leaflet; 2 - mosaic and leaf curl of the top of the plants/threading of newly developed leaves and mosaic/stunting and leaf curl of the top; and 3 - intense mosaic, leaf curl and stunting of the top of the plants (Fig. 2 Suppl.). PCR using primers TYC1F and TYC1R (Lapidot 2002), amplifying part of C1 gene and part of the IR (882 bp PCR product), was employed to detect TYLCV (Table 1 Suppl.). 
Small RNA library construction, deep sequencing and bioinformatics analysis: Deep sequencing analysis was performed so as to evaluate TYLCV-Mild siRNA profile in tomato plants and compare it with that after application of dsRNA onto them. Samples were taken from plants treated with: a) TYLCV (replication 1) exhibiting symptoms, b) TYLCV (replication 2) exhibiting symptoms, c) TYLCV+dsV2 without symptoms (healthy), d) TYLCV+dsV2 (replication 1) exhibiting symptoms, and e) TYLCV+dsV2 (replication 2) exhibiting symptoms. Total RNA was extracted from systemic leaves at $40 \mathrm{dpi}$, as bulk sample from three plants of each group. The negative control was healthy tissue deriving from watertreated tomato plants (mock). Samples were processed according to the Illumina TruSeq small RNA protocol of Fasteris SA (https://www.fasteris.com/dna/?q=content/ small-rna). A library of short inserts was prepared for each sample; inserts of 20 - $25 \mathrm{nt}$ were sequenced on an Illumina HiSeq 2500 instrument. Subsequently, insert-mapping with Burrows-Wheeler Alignment tool on TYLCV-Mild sequence (AF071228.1) and output conversion into BAM format using Samtools ( $\mathrm{Li}$ et al. 2009) was performed. The MISIS software (Seguin et al. 2014) was used for visualisation of the vsiRNAs reads, determination of their orientation and identification of the locations of low and high amount of them (cold and hot spots, respectively) for the TYLCV-Mild genome.

DsRNA stability and movement in tomato: The stability and movement of dsRNA in tomato was determined by rubbing dsV2 $(0.04 \mathrm{mg})$ at the adaxial leaf surface of two carborundum-dusted leaflets of different leaf on four tomato plants. Treated leaves were washed five times with Triton $X-100(0.05 \%)$ and finally with tap water. Leaf disks $(0.5 \mathrm{~cm}$ in diameter) from the application leaflets and from systemic/non-treated leaflets from all four plants were collected at $1 \mathrm{~h}$ post treatment (hpt), as well as at 1, 3, 6, 9,21 , and $54 \mathrm{dpt}$. These bulk samples were used for RNA extraction as described above and RNA concentration was determined spectrophotometrically. DsV2 was detected by reverse transcription (RT)- semi-quantitative PCR using the specific primers TYLCV-Mild\&IL-V2-F-T and TYLCV-Mild-V2-R-T designed in this work (Table 1 Suppl.). $50 \mathrm{ng}$ of RNA were denatured at $65^{\circ} \mathrm{C}-5 \mathrm{~min}$ with the primer TYLCV-Mild-V2-R-T $(0.1 \mu \mathrm{M})$ and dNTPs $(0.5 \mathrm{mM})$. Subsequently, hot mix was added with final concentrations of the components: $1 \times$ buffer, $2 \mathrm{U}$ reverse transcriptase, $10 \mathrm{mM}$ dithiotreitol (DTT); RT reaction was performed at $42{ }^{\circ} \mathrm{C}-50 \mathrm{~min}$ followed by a 15 min incubation at $70{ }^{\circ} \mathrm{C} .1 \mathrm{~mm}^{3}$ of the RT-product was used as a template for the subsequent PCR reaction, with conditions and final concentrations of the components as described for the dsRNA production. As negative controls for the RT and PCR reactions, we used tubes in which $\mathrm{H}_{2} \mathrm{O}$ was added instead of sample.

Detection of TYLCV-Mild-derived siRNAs by stemloop RT-PCR: Stem-loop RT-PCR (Varkonyi-Gasic et al. 2007) was applied to detect: $a$ ) six siRNAs (Table 1) in systemic tissue of tomato plants either inoculated with TYLCV (exhibiting symptoms) or inoculated with TYLCV+dsV2 (exhibiting symptoms or not), b) two siRNAs, namely siV2_352s and siV2 325as (Table 1), in local/treated and systemic/non-treated leaves of tomato plants where only dsV2 was applied; samples were collected at 1, 9, and 54 dpi.

Total RNA extraction was performed as described above. The negative control was healthy tissue deriving from water-treated tomato plants (mock). $100 \mathrm{ng}$ total RNA were denatured at $65^{\circ} \mathrm{C}-5 \mathrm{~min}$ and a specific reverse primer for each siRNA was used (Table 1 Suppl.). RT was performed with Superscript II reverse transcriptase (Thermo Fisher Scientifics) under the conditions $16^{\circ} \mathrm{C}-30 \mathrm{~min}, 60$ cycles of $30{ }^{\circ} \mathrm{C}-30 \mathrm{~s}, 42^{\circ} \mathrm{C}-30 \mathrm{~s}, 50^{\circ} \mathrm{C}-1 \mathrm{~s}$ and enzyme inactivation at $85{ }^{\circ} \mathrm{C}-5 \mathrm{~min}$, according to the stem-loop reverse transcription protocol (Varkonyi-Gasic et al. 2007). PCR was performed using KAPA Taq DNA polymerase, specific forward primers (Table 1 Suppl.) and the universal reverse primer; the thermal profile included 1 cycle of $94{ }^{\circ} \mathrm{C}-2 \mathrm{~s}$, 37 cycles of $94{ }^{\circ} \mathrm{C}-15 \mathrm{~s}$ and $60^{\circ} \mathrm{C}-1 \mathrm{~min}$. As a loading control, for normalization purposes, we checked the intensity of ribosomal RNA bands in gel electrophoresis.

Table 1. VsiRNAs (21-nt long) detected in this study by stem-loop RT-PCR. " - VsiRNA names having "s" or "as" as an ending designate vsiRNAs originating, respectively, from the sense or the antisense strand of the corresponding genes. ** - It was chosen from literature as the 511-531 nt hot spot for TYLCV-IL (Leibman et al. 2015, personal communication with Dr Gal-On and Dr Leibman). Blast tool (https://blast.ncbi.nlm.nih.gov/Blast.cgi) was employed to find the corresponding sequence in TYLCV-Mild genome. Based on small RNA sequencing analysis it was classified as cold spot for TYLCV-Mild. ${ }^{* * *}$ - It was chosen from literature as the 1761-1781 nt hot spot for TYLCV-IL (Leibman et al. 2015, personal communication with Dr Gal-On and Dr Leibman). It was classified as hot spot although its reads were not as high as other hot spots for TYLCV-Mild in our small RNA sequencing analysis. ${ }^{* * * *}$ - It is the sense clone of siC1 antisense_1596 (the above one in the table).

\begin{tabular}{lllll}
\hline Name $^{*}$ & Sequence (5' to 3') & $\begin{array}{l}\text { Region in TYLCV-Mild } \\
\text { genome }\end{array}$ & $\begin{array}{l}\text { Reads/NGS analysis } \\
\text { in this study }\end{array}$ & Reference \\
\hline siC1-C4_2471s & TTGCAGAGAACTCCACGAGAA & C1-C4; 2491-2471 & 36276 (hot spot) & This study \\
siC1-C4_2471as & TTCTCGTGGAGTTCTCTGCAA & C1-C4; 2471-2491 & 29 (cold spot) & This study \\
siV2_325as & AAATGATTATATCGCCTGGTC & V2;345-325 & 8604 (hot spot) & This study \\
siV2_352s & CCGCCTCGAAGGTTCGCCGAA & V2;352-372 & 2 (cold spot) & This study $^{* * *}$ \\
siC1_1596as & TGATACTTGCGAACAGTGGCT & C1;1596-1616 & 696 (hot spot) & This study $^{* * * *}$ \\
siC1_1616s & AGCCACTGTTCGCAAGTATCA & C1;1616-1596 & 11 (cold spot) & This study $^{* * * *}$ \\
\hline
\end{tabular}




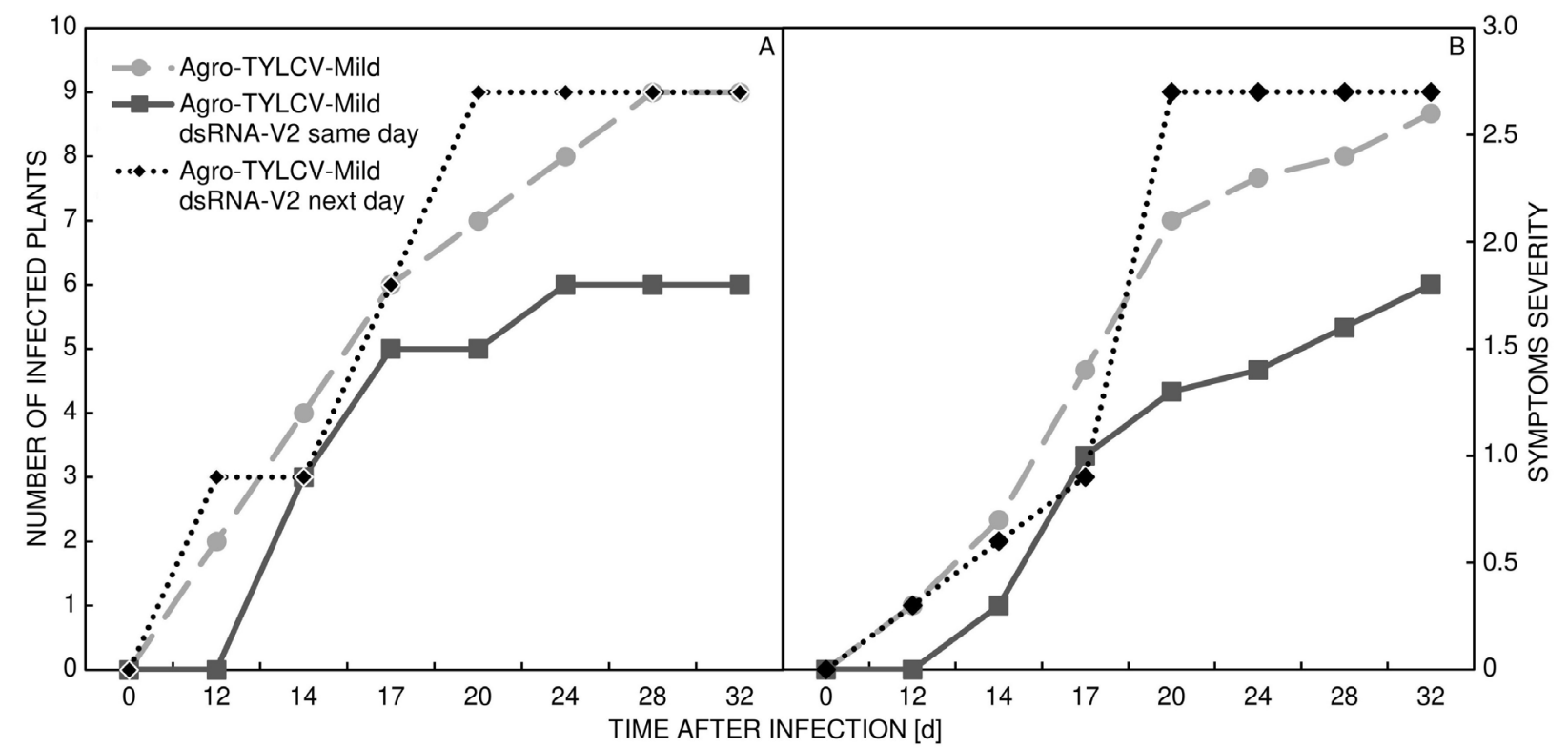

Fig. 1. Results of the first trial of dsV2 exogenous vaccination against TYLCV-Mild: disease occurrence in tomatoes treated with TYLCV (agroinfiltration), TYLCV+dsV2 (with dsRNA applied the same day), TYLCV+dsV2 (with dsRNA applied one day post agroinfiltration of the virus). $A$ - The line graph represents the number of infected plants per treatment over time. B - The line graph represents the symptoms severity evaluation of tomato plants per treatment according to the symptom severity scale. Application of dsV2 and TYLCV the same day reduced the number of infected plants and delayed the development of symptoms, comparing to treatments TYLCV and TYLCV+dsV2 (dsRNA application one day post virus agroinfiltration).

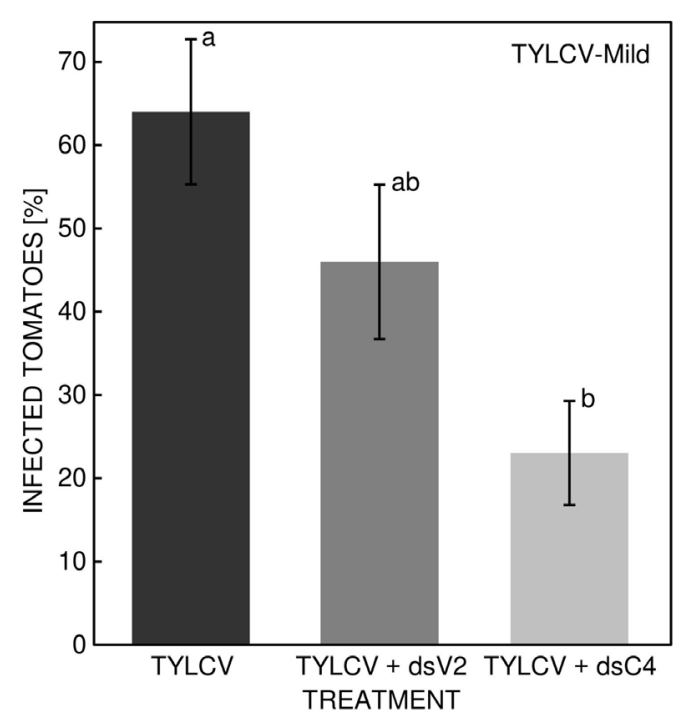

Fig. 2. Total results of the trials of dsV2 and dsC4 exogenous vaccination against TYLCV-Mild: mean disease occurrence in tomatoes of 4 and 5 independent experiments for TYLCV-Mild (for dsRNA C4 and V2, respectively). Virus presence was based on symptoms observation and PCR detection with gene specific primers. The histogram represents the percentage of TYLCVMild infected plants per treatment (TYLCV [agroinfiltration], TYLCV $+d s V 2$, TYLCV + dsC4). Means \pm SEs. Different letters stand for significantly different results, after the employment of ANOVA and Student's $t$-test $(P<0.05)$.

\section{Results}

DsRNA molecules deriving from TYLCV-Mild V2 and C4 genes (Fig. 1A Suppl.), were produced successfully employing the in vitro method with primers designed in this work (Table 1 Suppl.). The products of the first PCR, second PCR, and the in vitro transcription reaction for the V2 and C4 genes are presented in Fig. 1B Suppl. The concentration of the dsRNA molecules ( $\mathrm{dsV} 2$ and dsC4) was determined spectrophotometrically between 17 and $30 \mathrm{mg} \mathrm{cm}^{-3}$.

Inoculated tomato plants of the dsRNA-bioassays were monitored for TYLCV disease symptoms appearance employing a symptom severity scale (Fig. 2 Suppl.) until 40 - 60 dpi. Additionally, TYLCV-Mild presence was confirmed by PCR, verifying the visual symptoms (data not shown).

Topical application of $\mathrm{dsV} 2$ followed, on the same day, by TYLCV agroinfiltration of tomato $\mathrm{cv}$. Clodin led to a reduced number of infected plants $(60 \%$ infection, Fig. $1 A)$, with delayed symptom development (Fig. 1B). In contrast, when dsV2 was applied one day post agroinfiltration of TYLCV a $90 \%$ infection was observed, which was similar to the positive control plants inoculated with TYLCV without dsRNA application (Fig. 1A). Based on this result, in the following experiments the dsRNA-vaccines were applied on the same day as TYLCV agroinfiltration. From the five experiments conducted employing topical application of dsV2 and dsC4 it was observed that disease incidence was reduced to 46 and $23 \%$, respectively as compared to $64 \%$ obtained by TYLCV alone (Fig. 2, 


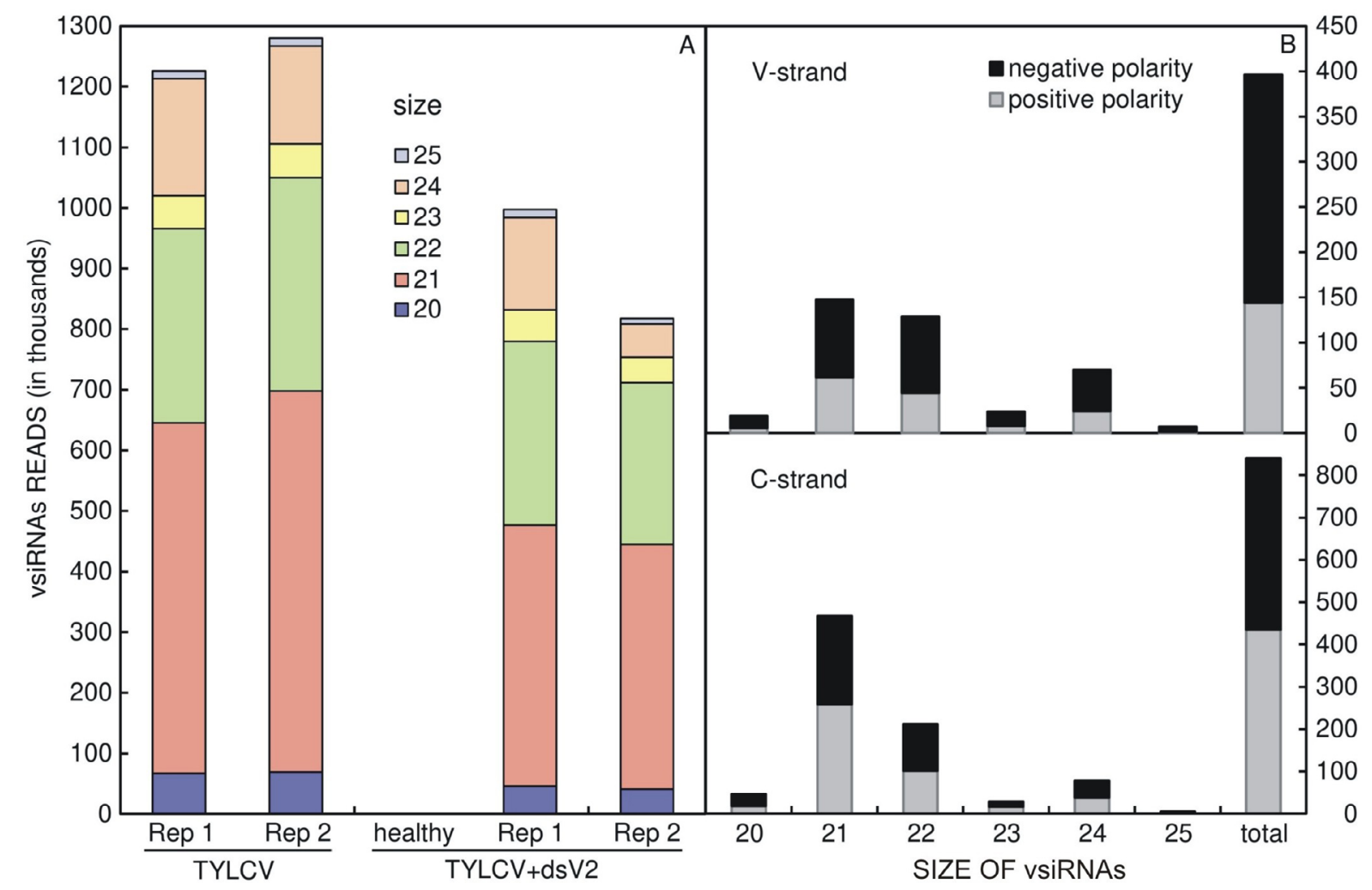

Fig. 3. Bioinformatics analysis of TYLCV-Mild-derived siRNAs in infected tomato plants, as identified by next generation RNA sequencing. RNA samples analyzed refer to tissue from plants treated with TYLCV exhibiting symptoms (replication 1, Rep 1; replication 2, Rep 2), TYLCV+dsV2 without symptoms (healthy), TYLCV+dsV2 exhibiting symptoms (replication 1, Rep1; replication 2, Rep 2). $A$ - Total reads of siRNAs and their size distribution (20-25 nt) identified in each sample. $B$ - Number of reads and polarity of 20-25 nt siRNAs deriving from the V-strand and the C-strand of TYLCV-Mild from tomato plants treated with TYLCV exhibiting symptoms (replication 2).

Table 2 Suppl.). Therefore, the protection of tomato plants achieved was 28 and $64 \%$ accordingly. ANOVA showed that there was a difference between the three treatments $(P=0.0218)$. Subsequent means comparison for each pair using Student's $t$-test indicated that TYLCV and TYLCV+dsC4 significantly differed $(P=0.0068)$, whereas no significant difference was observed between TYLCV and TYLCV $+\mathrm{dsV} 2(P=0.1494)$ as well as between TYLCV+dsV2 and TYLCV+dsC4 $(P=0.0893)$.

In order to study the profile of vsiRNAs of TYLCVMild genome and to investigate the effect of applied dsRNA to the vsiRNA population, a deep sequencing analysis was performed in tomato interacting with TYLCV-Mild. Deep sequencing analysis was performed in bulk samples of plants treated only with TYLCV exhibiting symptoms (replication 1 and 2), plants treated with TYLCV $+\mathrm{dsV} 2$ exhibiting symptoms (replication 1 and 2), or without symptoms (healthy). From a total number of 14319832 reads (vsiRNAs 20-25 nt) in sample from TYLCV-treated plants (replication 1), 9.1\% were mapped on the TYLCVMild genome (AF071228.1); similar percentage was obtained for the replication 2 of TYLCV-treated plants $(9.9 \%)$. However, when dsV2 was applied and plants were infected, the reads mapped on the TYLCV-Mild genome decreased to 6.2 and $7.6 \%$ (replication 1 and 2); and when plants were TYLCV-free (confirmed by PCR detection) the vsiRNA reads were practically negligible (Fig. $3 A$ ). Interestingly, the C-strand had a twofold of vsiRNAs (size 20-25 nt) as compared to that of the V-strand (compare total reads in upper and lower panels, Fig. 3B). $5^{\prime}$-U (uridine) and $5^{\prime}$-A (adenosine) were more abundant in TYLCV 21nt vsiRNAs ( $5^{\prime}$-U being slightly dominant). For V2 gene, there was a bias for $5^{\prime}-\mathrm{A}(\sim 40 \%)$ and for $\mathrm{C} 4$ a bias for 5'-C (cytosine) ( $45 \%$ ) (Fig. 3 Suppl.).

In all small RNA libraries, 21 and 22-nt vsiRNAs were the most abundant, followed by the 24-nt (Fig. $3 A$ ). The visualization of TYLCV-siRNAs was done by MISIS (Seguin et al. 2014) and revealed that siRNAs were asymmetrically distributed in the TYLCV-Mild genome and that the distribution pattern of 21-nt resembled that of the total 20-25 nt vsiRNAs (Fig. 4 Suppl.). TYLCV-siRNAs of negative polarity (in respect to the transcriptional unit) were slightly more abundant than those of positive polarity (53.5 vs. $46.6 \%$ ) in the length of its genome. Although positive and negative polarity vsiRNAs were almost equal in the C-strand, vsiRNAs of negative polarity prevailed in the V-strand (63.5 vs. $36.5 \%$ ) (Fig. 3B).

Bioinformatics analysis and subsequent visualization of the TYLCV-siRNAs by MISIS identified cold and hot spots (Fig. 4 Suppl.). In particular, in C-strand the 21-nt siC1-C4_2471s (positive polarity), located at the beginning of $\mathrm{C} 4$ gene (included in overlapping C1 gene) with 36276 
A

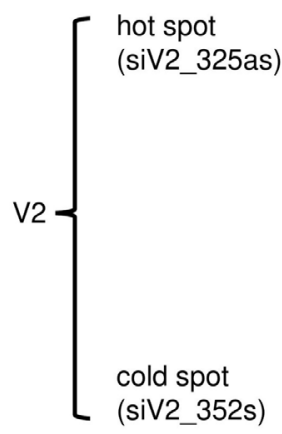

B

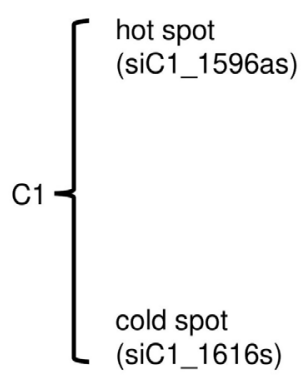

C
Mock TYLCV TYLCV+dsV2

(healthy) M (Rep 1 Rep 2) (healthy Rep 1 Rep 2)
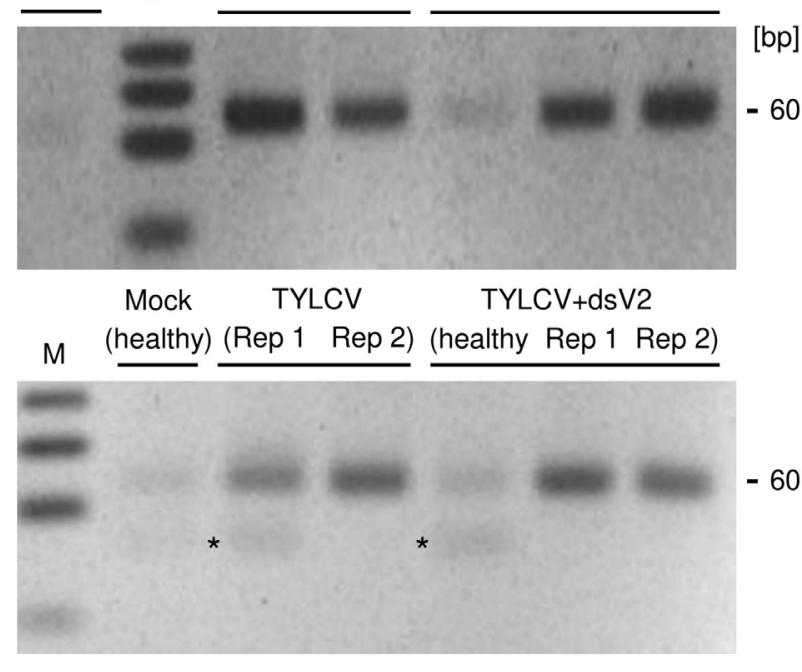

Mock TYLCV TYLCV+dsV2

M (healthy) (Rep 1 Rep 2) (healthy Rep 1 Rep 2)

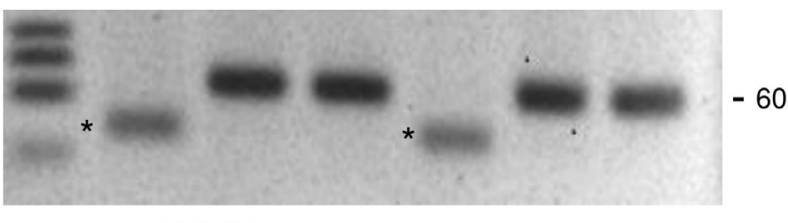

Mock TYLCV TYLCV+dsV2

(healthy) (Rep 1 Rep 2) (healthy Rep 1 Rep 2)

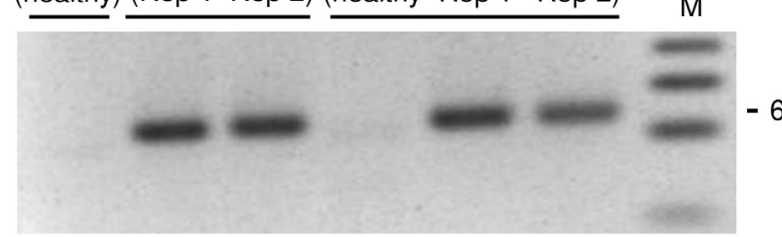

Mock TYLCV TYLCV+dsV2

(healthy) M (Rep 1 Rep 2) (healthy Rep 1 Rep 2)

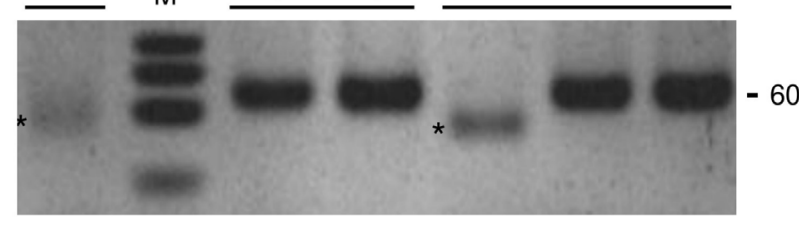

Mock TYLCV TYLCV+dsV2

(healthy) M $\underline{(\operatorname{Rep} 1 \text { Rep 2) (healthy Rep } 1 \text { Rep 2) }}$

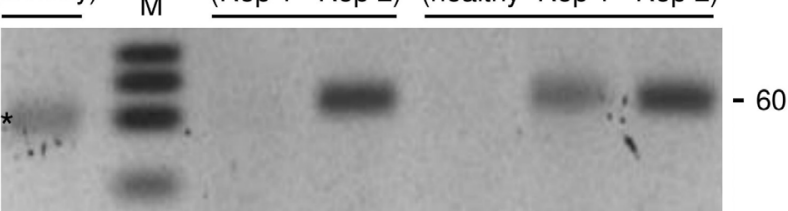

Fig. 4. Detection of six specific TYLCV-Mild siRNAs (hot and cold spots) deriving from $A$ - V2 gene, $B$ - C1 gene, $C$ - common region of $\mathrm{C} 1$ and $\mathrm{C} 4$ genes, in tomato plants treated only with TYLCV exhibiting symptoms (replication 1, Rep 1; replication 2, Rep 2) and with TYLCV+dsV2 either symptomless (healthy), or exhibiting symptoms (replication 1, Rep 1; replication 2, Rep 2). These siRNAs were chosen from literature for TYLCV-IL (siV2_352s, siC1_1596as, siC1_1616s) and deep sequencing bioinformatics analysis of RNA samples deriving from plants infected with TYLCV exhibiting symptoms (replication 2) (siV2_325as, siC1-C4_2471s, siC1-C4_2471as). A pool of three plants from each category was used for RNA extraction of systemic leaf tissue/non-treated leaves at 40 dpi. The semi-quantitative stem-loop RT-PCR method (Varkonyi-Gasic et al. 2007) was employed. The negative control was healthy tissue deriving from water-treated tomato plants (mock). The specific siRNAs were poorly or not at all amplified in plants treated with TYLCV $+\mathrm{dsV} 2$ without symptoms. * - designates a non-specific PCR amplification product. 
A

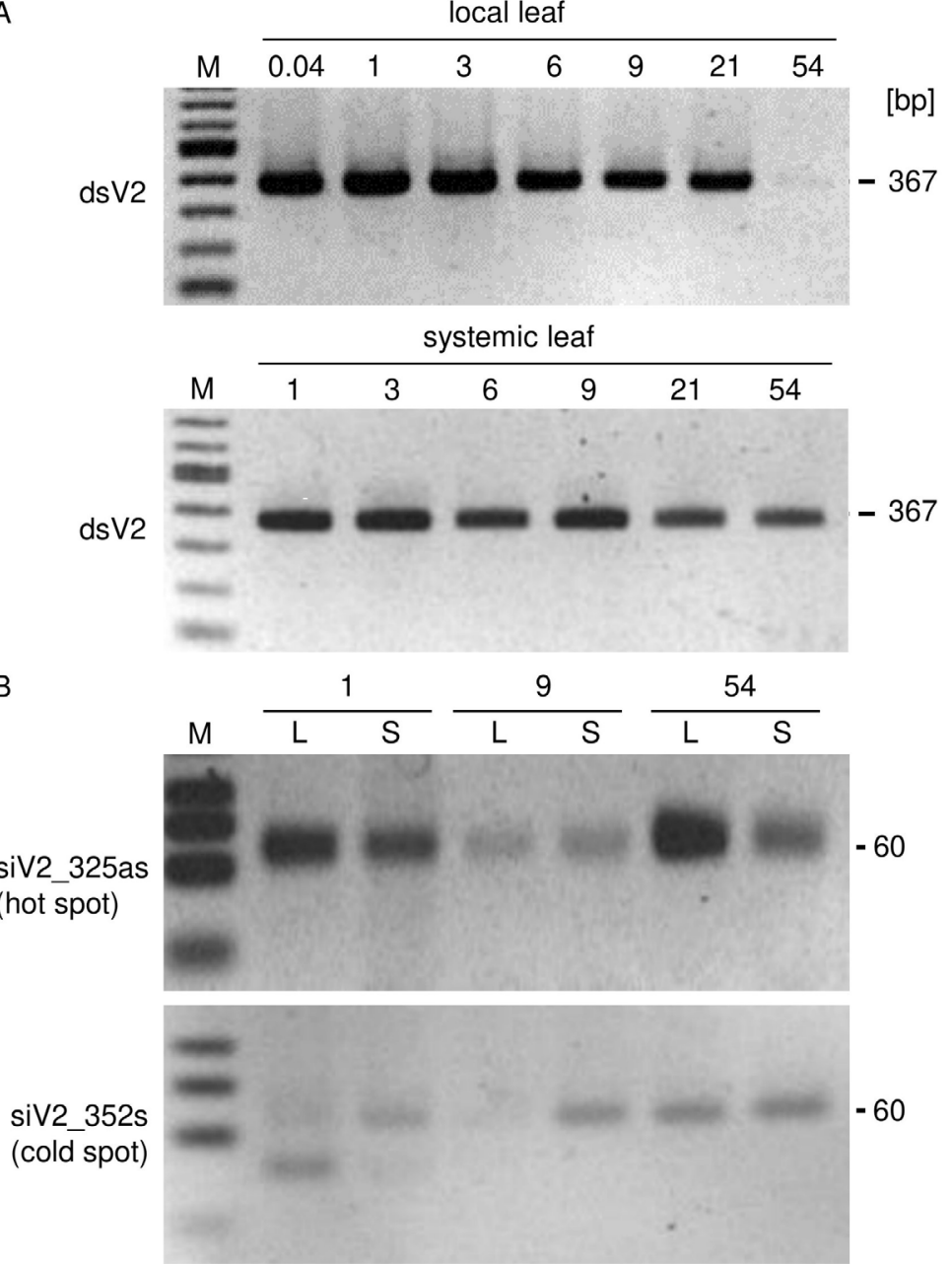

Fig. 5. Detection of dsV2 and of specific sequence viral siRNAs deriving from TYLCV-Mild V2 gene in local/treated and systemic/ non-treated leaves of tomato plants. $A$ - DsV2 was exogenously applied onto two leaflets of different leaves per plant. Tissue samples were taken from a pool of four plants and used for RNA extraction at 0.04 (1-h post treatment), 1, 3, 6, 9, 21, and 54 dpt. DsV2 was amplified by semi-quantitative RT-PCR. $B$ - The siRNAs, siV2 352s and siV2 325as, were detected at the local/treated leaf (L) and the systemic leaf (S) by semi-quantitative stem-loop RT-PCR according to Varkonyi-Gasic et al. (2007). The RNA samples at 1, 9, and $54 \mathrm{dpt}$ were used for the siRNAs' detection.

reads (Fig. $5 A$ Suppl.), was the hottest spot of the genome; in the V-strand, the 21-nt siV2 325as (negative polarity), located at the common region of $\mathrm{V} 1 / \mathrm{V} 2$ genes, was the hottest 21-nt spot with 8604 reads (Table 1), whereas the hottest spot of 20-25 nt vsiRNAs for the V-strand was observed at V1 gene ending at 524 nt (negative polarity, 24734 reads). The distribution of the cold and hot spots of vsiRNAs was similar in all the libraries deep sequenced in this study.

Six vsiRNAs (see Table 1) were validated by stem loop RT-PCR (Fig. 4). SiRNAs from hot spots (siV2_325as, siC1-C4_2471s and siC1_1596as) were strongly amplified when compared to siV̌ 352 s (identified as hot spot for TYLCV-IL; Leibman, personal communication), siC1_1616s and siC1-C4_2471as that derived from cold spots (Fig. 4). Additionally, in plants that received TYLCV+dsV2 and did not show disease symptoms, two vsiRNAs were poorly and four vsiRNAs were not amplified (Fig. 4). In conclusion, the stem-loop RT-
PCR method successfully detected siRNAs, confirming the deep sequencing analysis data, while siRNAs were poorly or not at all detected in non-diseased plants where TYLCV+dsV2 was applied.

DsV2 (0.04 mg), exogenously applied onto two leaflets of different leaves in tomato, was detected until 54 dpi employing semi-quantitative RT-PCR at the local/ application leaflet and the same systemic leaf. In the application leaf, the dsV2 was detected at $1 \mathrm{hpt}$, with its quantity decreasing after $3 \mathrm{dpt}$, detected up to $21 \mathrm{dpt}$ and was barely detectable at $54 \mathrm{dpt}$ (Fig. $5 \mathrm{~A}$ ). At the systemic tissue, dsRNA was detected from $1 \mathrm{dpt}$, was relatively stable and was identified even at $54 \mathrm{dpt}$ (Fig. $5 \mathrm{~A}$ ).

To confirm that the exogenously applied dsV2 is processed in tomato, specific vsiRNAs were detected by semi-quantitative stem-loop RT-PCR in local/treated and systemic/non-treated leaves of tomato plants at 1,9, and 54 dpt. In particular, the siV2 352s (352-372 nt) (Leibman et al. 2015) and siV2_325as (345-325 nt) (this study), located 
in V2 gene within dsV2, were used as the vsiRNAs under detection. The siV2 352s was amplified in both local and systemic leaves (Fig. 5B), giving faint bands, confirming that derives from a TYLCV-Mild cold spot, as it was visualized with MISIS (Fig. 5B Suppl.). Interestingly, at 54 dpt siV2_352s showed a small increase (Fig. $5 B$ ). On the other hand, the siV2 325as was strongly amplified in both local and systemic leaves, verifying that it consists a hot spot with a slight increase at $54 \mathrm{dpt}$, especially at the local leaflet (Fig. 5B).

\section{Discussion}

Until now there was no application of RNA-based vaccination method in monopartite begomoviruses. In this study, we aimed at conferring resistance against TYLCV exploiting tomato's RNAi through topical application of dsRNAs from two regions of TYLCV genome, namely sequences of TYLCV-Mild V2 and C4 silencing suppressor genes. The dsRNAs were produced in vitro (Fig. 1B Suppl.) and topically applied as vaccines onto tomato plants against TYLCV-Mild.

Topical application of dsRNA-vaccines induced resistance against agroinfiltrated TYLCV-Mild strain in tomato. $\mathrm{DsV} 2$ and $\mathrm{dsC} 4$ reduced disease incidence to 46 and $23 \%$, respectively, while TYLCV-inoculated plants were infected at a level of $64 \%$; this corresponds to protection of 28 and $64 \%$, respectively, falling within the protection range obtained through RNA-based vaccination against RNA viruses (Holeva et al. 2021, Konakalla et al. 2016, Kaldis et al. 2018). V2 and C4 genes are considered to be TYLCV silencing suppressors (Vanitharani et al. 2004, Glick et al. 2008). The higher protection accomplished with dsC4 stems from the fact that C4 protein is also involved in TYLCV movement (Jupin et al. 1994, Rojas et al. 2001, Hak et al. 2015). In addition, $\mathrm{C} 4$ gene is positioned within $\mathrm{C} 1$, which has also been used in PDR (Fuentes et al. 2016). Another possible explanation is that $\mathrm{C} 1$ and $\mathrm{C} 4$ are early transcripts in geminiviruses as compared to the virion-sense transcripts (Borah et al. 2016). NGS analysis indicated that C4 gene has 132672 21-nt vsiRNAs whereas V2 has 66488 21-nt vsiRNAs. Since the 21-nt siRNAs are considered the most important siRNAs in antiviral defence (Wang et al. 2011), the observation that the $\mathrm{C} 4$ sequence produces a higher number of vsiRNA reads as compared to V2 sequence, could explain the higher protective efficiency of the applied dsC4.

NGS analysis of small RNAs was performed in TYLCVinfected tomato in order to determine the TYLCV-Mild wide distribution of siRNAs. VsiRNAs sized 21 and 22-nt were predominant as found for TYLCV (Cuban isolate) (Fuentes et al. 2016), TYLCV-IL (X15656.1) (Leibman et al. 2015) and TYLCSV (Miozzi et al. 2013), followed by those of 24-nt. The latter is in contrast to the findings of Miozzi et al. (2013) and Leibman et al. (2015) who reported that the population of the 21 and 22-nt vsiRNAs were followed by that of 20-nt.

VsiRNAs reads (size 20-25 nt) of the C-strand were twofold of those of the V-strand (Fig. 3B) as was found for TYLCSV (31 and $68 \%$ of reads from the V-and C-strand, respectively, Miozzi et al. 2013). Positive and negative polarity vsiRNAs were almost equal at the C-strand, whereas vsiRNAs of negative polarity prevailed (63.5 vs. $36.5 \%$ ) at the V-strand. As a result, the total vsiRNAs of negative polarity were slightly more abundant than those of positive polarity (53.5 vs. $46.6 \%$ ). In contrast to our study, almost equal positive and negative polarity vsiRNAs were found for TYLCV (Fuentes et al. 2016) and for TYLCSV, 49 and $51 \%$, respectively (Miozzi et al. 2013).

MISIS visualization tool presented the hot spots of 20-25 nt siRNAs of the TYLCV-Mild genome. SiC1C4_2471s is the hottest spot (36 276 reads) located at the beginning of $\mathrm{C} 4$ gene (included in overlapping $\mathrm{C} 1$ gene, positive polarity). Other studies on TYLCV have also identified the hottest siRNA spot at the C-strand; in particular at a common region of C1-C4 (2 227-2 $279 \mathrm{nt})$ (Miozzi et al. 2013), at the common region of $\mathrm{C} 2-\mathrm{C} 3$ (Fuentes et al. 2016) and at a common region of $\mathrm{C} 1$ C2 genes (Leibman et al. 2015). For the V-strand, the highest peak was spotted ending at 524-nt of V1 (negative polarity, 24734 reads), whereas for TYLCSV was located at a common/overlapping region of V2-V1 genes (454$480 \mathrm{nt}$ ) (Miozzi et al. 2013). In all small RNA libraries, the distribution and abundance pattern of 20-25-nt vsiRNAs was similar. This may imply that the specified activity of DCLs in tomato is not influenced by the dsRNAs topical application.

AGOs of Arabidopsis thaliana have been found to bind to siRNAs showing a 5' terminal nucleotide bias, namely $\mathrm{U}(86 \%)$ in the case of AGO1, A (93\%) for AGO2, A (79\%) for AGO4, and C (83\%) for AGO5 (Mi et al. 2008). The 5'-nucleotide profile of vsiRNAs in tomato-TYLCV-Mild interaction was obtained with MISIS determining that the majority of 21-nt in TYLCV-treated tomato exhibiting symptoms, were $5^{\prime}-\mathrm{U}$ and $5^{\prime}-\mathrm{A}$, with $5^{\prime}$-U being slightly higher. Specifically, for V2 gene, $21-n t$ had a bias to $5^{\prime}-\mathrm{A}$ (almost $40 \%$ ), whereas for $\mathrm{C} 4$ gene, 21-nt had a bias to 5 '-C (about $45 \%$ ). Based on these observations and considering the 5 'terminal nucleotide profile in siRNAs of $A$. thaliana it is expected that the majority of 21-nt TYLCV-Mild vsiRNAs are associated mostly with AGOs 1,2 and 4, while majority of $\mathrm{C} 4$ deriving vsiRNAs is associated with AGO5. Fuentes et al. (2016) also determined that $5^{\prime}$-A 21-nt vsiRNAs were the most abundant followed by $5^{\prime}-\mathrm{U}$ in TYLCV-infected tomato. Contrary to these findings, Miozzi et al. (2013) found a preference of TYLCSV siRNAs to $5^{\prime}-\mathrm{C}$. The composition mismatches, the different sequencing analysis, the time of sampling and the severity of tomato infection at that time should be factored in as reasons for the differences at the presented TYLCV-Mild siRNA profile with those of TYLCSV, TYLCV-IL and TYLCV.

The above-mentioned NGS analysis was also employed to determine the effect of the applied dsRNA in siRNAs population (TYLCV-Mild infection) between plants treated with TYLCV and TYLCV+dsV2. VsiRNAs decreased from 9.9 and $9.1 \%$ (TYLCV-treated) to 7.6 and $6.2 \%$ in TYLCV $+\mathrm{dsV} 2$-treated plants exhibiting 
symptoms and almost eliminated in the non-infected (healthy) plants after dsRNA treatment, being in line with the absence of symptoms and proving the effectiveness of the dsRNA-vaccine against TYLCV-Mild proliferation.

In order to detect any differences in siRNAs abundance between tomato plants treated with TYLCV and with TYLCV+dsV2, systemic tissue was studied for the presence of six specific sequence $21-n t$ vsiRNAs. Semiquantitative stem-loop RT-PCR was employed (Kaldis et al. 2018) and the 21-nt vsiRNAs selected were detected (Fig. 4), confirming the deep sequencing analysis data. In non-diseased plants, where TYLCV+dsV2 was applied, there was a poor or no detection of vsiRNAs, whereas in diseased plants a strong detection of hot spots and weaker or no amplification of cold spots was observed.

The detection of dsRNA in young systemic/nontreated leaves of tomato where dsV2 was applied, proves its ability to move systemically at a fast rate $(1 \mathrm{dpt}$; Fig. $5 A$ ). In addition, the detection of dsRNA for $21 \mathrm{~d}$ and for at least $54 \mathrm{~d}$ at the application leaf and at younger leaves respectively, suggests their relative stability in tomato. In tobacco the applied dsRNA was strongly RTPCR amplified at $3 \mathrm{dpt}$ at the treated and systemic leaf, whereas at $6 \mathrm{dpt}$ was poorly amplified only at the treated leaf (Konakalla et al. 2016). In squash and watermelon, dsRNA was detected for 9 and $21 \mathrm{dpt}$ at the treated and systemic leaf, respectively (Kaldis et al. 2018). In support of the above, stem-loop RT-PCR detected 21-nt vsiRNAs at the local/treated and systemic/non-treated leaves for at least $54 \mathrm{dpt}$ (Fig. 5B). Based on the results obtained, we noticed a correlation between the absence of dsRNA (54 $\mathrm{d}$ post application in the local leaf) and the presence of siV2_325as which originates from a hot spot region. On the other hand, the presence of dsRNA (54 d post application in the systemic leaf) correlates with relatively low abundance of siV2_325as. These results strongly suggest the recognition and continuous processing of the topically applied dsRNA via DCLs in tomato. In a nonmutually exclusive explanation, siRNAs from hot spots might exhibit a higher stability in planta.

Topical application of dsRNA-vaccines overcomes the time-consuming, costly and complex method of transgenic plant production and its possible negative impacts (Tepfer 2002). Additionally, this novel method is advantageous over pesticides, since the intensive use of chemicals, the risks to humans and the insecticide resistance development are avoided.

The proof of concept of RNA-based vaccination against TYLCV needs to be followed by more experimentation to define the mode/time/number of applications and the appropriate dose. It is important to stress that the protective results of topical application of dsRNA-based vaccines (RBVs) against a monopartite DNA virus, such as TYLCV, are reported for the first time and are encouraging for the inclusion of this non-transgenic method in the integrated pest management of tomato against TYLCV. RNA vaccines could also be designed to target endogenous plant genes (e.g. susceptibility genes) in order to induce resistance in TYLCV hosts.

\section{References}

Abhary, M.K., Anfoka, G.H., Nakhla, M.K., Maxwell, D.P.: Post-transcriptional gene silencing in controlling viruses of the Tomato yellow leaf curl virus complex. - Arch. Virol. 151: 2349-2363, 2006.

Antignus, Y., Vunsh, R., Lachman, O., Pearlsman, M., Maslenis, L., Hananya, U., Rosner, A.: Truncated Rep gene originated from tomato yellow leaf curl virus-Israel [Mild] confers strain-specific resistance in transgenic tomato. - Ann. appl. Biol. 144: 39-44, 2004.

Bar-Ziv, A., Levy, Y., Citovsky, V., Gafni, Y.: The Tomato yellow leaf curl virus (TYLCV) V2 protein inhibits enzymatic activity of the host papain-like cysteine protease CYP1. Biochem. biophys. Res. Commun. 460: 525-529, 2015.

Bendahmane, M., Gronenborn, B.: Engineering resistance against tomato yellow leaf curl virus (TYLCV) using antisense RNA. - Plant mol. Biol. 33: 351-357, 1997.

Borah, B.K., Zarreen, F., Baruah, G., Dasgupta, I.: Insights into the control of geminiviral promoters. - Virology 495: 101-111, 2016.

Brown, J., Fauquet, C., Briddon, R., Zerbini, M., Moriones, E., Navas-Castillo, J., King, A., Adams, M., Carstens, E., Lefkowitz, E.: Geminiviridae. - In: King, A., Lefkowitz, E., Adams, M.J., Carstens, E.B. (ed.): Virus taxonomy: ninth report of the International Committee on Taxonomy of Viruses, $1^{\text {st }}$ ed. Pp. 351-373. Elsevier, London 2012.

Chellappan, P., Vanitharani, R., Fauquet, C.M.: MicroRNAbinding viral protein interferes with Arabidopsis development. - Proc. nat. Acad. Sci. USA 102: 10381-10386, 2005.

De Barro, P.J., Liu, S.-S., Boykin, L.M., Dinsdale, A.B.: Bemisia tabaci: a statement of species status. - Annu. Rev. Entomol. 56: 1-19, 2011.

Dellaporta, S.L., Wood, J., Hicks, J.B.: A plant DNA minipreparation: version II. - Plant mol. Biol. Rep. 1: 19-21, 1983.

Diaz-Pendon, J.A., Canizares, M.C., Moriones, E., Bejarano, E.R., Czosnek, H., Navas-Castillo, J.: Tomato yellow leaf curl viruses: ménage à trois between the virus complex, the plant and the whitefly vector. - Mol. Plant Pathol. 11: 441450, 2010.

Duan, C.-G., Wang, C.-H., Guo, H.-S.: Application of RNA silencing to plant disease resistance. - Silence 3: 5, 2012.

Fuentes, A., Carlos, N., Ruiz, Y., Callard, D., Sánchez, Y., Ochagavía, M.E., Seguin, J., Malpica-López, N., Hohn, T., Lecca, M.R., Pérez, R., Doreste, V., Rehrauer, H., Farinelli, L., Pujol, M., Pooggin, M.M.: Field trial and molecular characterization of RNAi-transgenic tomato plants that exhibit resistance to Tomato Yellow Leaf Curl Geminivirus. Mol. Plant-Microbe Interact. 29: 197-209, 2016.

Gafni, Y.: Pathogen profile, Tomato yellow leaf curl virus, the intracellular dynamics of a plant DNA virus. - Mol. Plant Pathol. 4: 9-15, 2003.

Garcia-Andres, S., Monci, F., Navas-Castillo, J., Moriones, E.: Begomovirus genetic diversity in the native plant reservoir Solanum nigrum: evidence for the presence of a new virus species of recombinant nature. - Virology 350: 433-442, 2006.

Glick, E., Zrachya, A., Levy, Y., Mett, A., Gidoni, D., Belausov, E., Citovsky, V., Gafni, Y.: Interaction with host SGS3 is required for suppression of RNA silencing by tomato yellow leaf curl virus V2 protein. - Proc. nat. Acad. Sci. USA 105: 157-161, 2008.

Hak, H., Levy, A., Chandran, S.A., Belausov, E., Loyter, A., Lapidot, M., Gafni, Y.: TYLCV-Is movement in planta does not require V2 protein. - Virology 477: 56-60, 2015.

Holeva, M.C., Sclavounos, A.P., Rajeswaran, R., Pooggin, M.M., 
Voloudakis, A.E.: Topical application of double-stranded RNA targeting $2 \mathrm{~b}$ and $\mathrm{CP}$ genes of Cucumber mosaic virus protects plants against local and systemic viral infection. Plants (accepted for publication), 2021.

Juárez, M., Tovar, R., Fiallo-Olivé, E., Aranda, M.A., Gosálvez, B., Castillo, P., Moriones, E., Navas-Castillo, J.: First detection of Tomato leaf curl New Delhi virus infecting zucchini in Spain. - Plant Dis. 98: 857, 2014.

Jupin, I., De Kouchkovsky, F., Jouanneau, F., Gronenborn, B.: Movement of Tomato Yellow Leaf Curl Virus (TYLCV): involvement of the protein encoded by ORF C4. - Virology 204: 82-90, 1994.

Kaldis, A., Berbati, M., Melita, O., Reppa, C., Holeva, M., Otten, P., Voloudakis, A.E.: Exogenously applied dsRNA molecules deriving from the Zucchini yellow mosaic virus (ZYMV) genome move systemically and protect cucurbits against ZYMV. - Mol. Plant Pathol. 19: 883-895, 2018.

Konakalla, N.C., Kaldis, A., Berbati, M., Masarapu, H., Voloudakis A.E.: Exogenous application of double-stranded RNA molecules from TMV p126 and CP genes confers resistance against TMV in tobacco. - Planta 244: 961-969, 2016.

Konakalla, N.C., Kaldis, A., Masarapu, H., Voloudakis, A.E.: Topical application of double stranded RNA molecules deriving from Sesbania mosaic virus (SeMV) CP and MP genes protects Sesbania plants against SeMV. - Eur. J. Plant Pathol. 155: 1345-1352, 2019.

Lapidot, M.: Screening common bean (Phaseolus vulgaris) for resistance to Tomato yellow leaf curl virus. - Plant Dis. 86: 429-432, 2002.

Lapidot, M., Levin, I.: Genetic resistance to viruses in tomato. - In: Mattoo, A., Handa, A. (ed.): Achieving sustainable cultivation of tomatoes. Pp. 381-393. Burleigh Dodds Science Publishing, Cambridge 2017.

Lefeuvre, P., Martin, D.P., Harkins, G., Lemey, P., Gray, A.J.A., Meredith, S., Lakay, F., Monjane, A., Lett, J.-M., Varsani, A., Heydarnejad, J.: The spread of Tomato Yellow Leaf Curl Virus from the middle east to the world. - PLoS Pathogens 6: e1001164, 1-12, 2010.

Leibman, D., Prakash, S., Wolf, D., Zelcer, A., Anfoka, G., Haviv, S., Brumin, M., Gaba, V., Arazi, T., Lapidot, M., Gal-On, A.: Immunity to tomato yellow leaf curl virus in transgenic tomato is associated with accumulation of transgene small RNA. - Arch. Virol. 160: 2727-2739, 2015.

Li, H., Handsaker, B., Wysoker, A., Fennell, T., Ruan, J., Homer, N., Marth, G., Abecasis, G., Durbin, R.: The sequence alignment/map format and SAM tools. - Bioinformatics 25: 2078-2079, 2009.

Mi, S., Cai, T., Hu, Y., Chen, Y., Hodges, E., Ni, F., Wu, L., Li, S., Zhou, H., Long, C., Chen, S., Hannon, G.J., Qi, Y.: Sorting of small RNAs into Arabidopsis argonaute complexes is directed by the 5' terminal nucleotide. - Cell 133: 116-127, 2008.

Miozzi, L., Pantaleo, V., Burgyan, J., Accotto, G.P., Noris, E.: Analysis of small RNAs derived from tomato yellow leaf curl Sardinia virus reveals a cross reaction between the major viral hotspot and the plant host genome. - Virus Res. 178: 287-296, 2013.

Moriones, E., Navas-Castillo, J.: Tomato yellow leaf curl virus, an emerging virus complex causing epidemics worldwide. Virus Res. 71: 123-134, 2000.

Namgial, T., Kaldis, A., Chakraborty, S., Voloudakis, A.: Topical application of double-stranded RNA molecules containing sequences of Tomato leaf curl virus and Cucumber mosaic virus confers protection against the cognate viruses. - Physiol. mol. Plant Pathol. 108: 101432, 2019.

Navas-Castillo, J., Sánchez-Campos, S., Noris, E., Louro, D., Accotto, G.P., Moriones, E.: Natural recombination between Tomato yellow leaf curl virus-Is and Tomato leaf curl virus. J. gen. Virol. 81: 2797-2801, 2000.

Noris, E., Accotto, G.P., Tavazza, R., Brunetti, A., Crespi, S., Tavazza M.: Resistance to Tomato yellow leaf curl geminivirus in Nicotiana benthamiana plants transformed with a truncated viral C1 gene. - Virology 224: 130-138, 1996.

Rojas, M.R., Jiang, H., Salati, R., Xoconostle-Cázares, B., Sudarshana, M.R., Lucas, W.J., Gilbertson, R.L.: Functional analysis of proteins involved in movement of the monopartite begomovirus, Tomato yellow leaf curl virus. - Virology 291: 110-125, 2001.

Seguin, J., Otten, P., Baerlocher, L., Farinelli, L., Pooggin, M.M.: MISIS: A bioinformatics tool to view and analyze maps of small RNAs derived from viruses and genomic loci generating multiple small RNAs. - J. Virol. Methods 195: 120-122, 2014.

Sanford, J.C., Johnston, S.A.: The concept of parasite-derived resistance. Deriving resistance genes from the parasite's own genome. - J. theor. Biol. 113: 395-405, 1985.

Stewart, C.N., Jr., Via, L.E.: A rapid CTAB DNA isolation technique useful for RAPD fingerprinting and other PCR applications. - Biotechniques 14: 748-750, 1993.

Tenllado, F., Díaz-Ruíz, J.R.: Double-stranded RNA-mediated interference with plant virus infection. - J. Virol. 75: 1228812297, 2001.

Tepfer, M.: Risk assessment of virus-resistant transgenic plants. - Annu. Rev. Phytopathol. 40: 467-491, 2002.

Vadlamudi, T., Patil, B.L., Kaldis, A., Sai Gopal, D.V.R., Mishra, R., Berbati, M., Voloudakis, A.: DsRNA-mediated protection against two isolates of Papaya ringspot virus through topical application of dsRNA in papaya. - J. virol. Methods 275: $113750,2020$.

Vanitharani, R., Chellappan, P., Pita, J.S., Fauquet, C.M.: Differential roles of AC2 and AC4 of cassava geminiviruses in mediating synergism and suppression of posttranscriptional gene silencing. - J. Virol. 78: 9487-9498, 2004.

Varkonyi-Gasic, E., Wu, R., Wood, M., Walton, E.F., Hellens, R.P.: Protocol: a highly sensitive RT-PCR method for detection and quantification of microRNAs. - Plant Methods 3: $12,2007$.

Voloudakis, A.E., Holeva, M.C., Sarin, L.P., Bamford, D.H., Vargas, M., Poranen, M.M., Tenllado, F.: Efficient doublestranded RNA production methods for utilization in plant virus control. - Methods Mol. Biol. 1236: 255-274, 2015.

Wang, X.B., Jovel, J., Udomporn, P., Wang, Y., Wu, Q., Li, W.X., Gasciolli, V., Vaucheret, H., Ding, S.W.: The 21-nucleotide, but not 22-nucleotide, viral secondary small interfering RNAs direct potent antiviral defense by two cooperative argonautes in Arabidopsis thaliana. - Plant Cell 23: 1625-1638, 2011.

Yin, G., Sun, Z., Liu, N., Zhang, L., Song, Y., Zhu, C., Wen, F.: Production of double-stranded RNA for interference with TMV infection utilizing a bacterial prokaryotic expression system. - Appl. Microbiol. Biotechnol. 84: 323-333, 2009.

Zrachya, A., Glick, E., Levy, Y., Arazi, T., Citovsky, V., Gafni, Y.: Suppressor of RNA silencing encoded by Tomato yellow leaf curl virus-Israel. - Virology 358: 159-165, 2007a.

Zrachya, A., Kumar, P.P., Ramakrishnan, U., Levy, Y., Loyter, A., Arazi,Tz., Lapidot, M., Gafni, Y.: Production of siRNA targeted against TYLCV coat protein transcripts leads to silencing of its expression and resistance to the virus. Transgenic Res. 16: 385-398, $2007 \mathrm{~b}$.

(C) The authors. This is an open access article distributed under the terms of the Creative Commons BY-NC-ND Licence. 